\title{
Nota
}

\section{RETENÇÃO DE SEDIMENTOS REMOVIDOS DE ÁREA DE LAVOURA PELA MATA CILIAR, EM GOIATUBA (GO) $)^{(1)}$}

\author{
Diléia Santana dos Santos ${ }^{(2)} \&$ Gerd Sparovek $^{(3)}$
}

\begin{abstract}
RESUMO
Matas ciliares são geralmente associadas à retenção de sedimentos e à mitigação dos impactos extrínsecos da erosão do solo em áreas de lavoura. No entanto, existem poucos estudos quantitativos sobre o tema. O objetivo deste trabalho foi analisar a eficiência de uma mata ciliar na retenção dos sedimentos produzidos na área de lavoura utilizando a técnica do ${ }^{137} \mathrm{Cs}$. A amostragem foi realizada em julho de 2005, em transector alocado em área sob intenso uso agrícola, na região central do Brasil, cultivada com algodão em sistema de plantio convencional. A técnica do ${ }^{137} \mathrm{Cs}$ mostrou-se adequada para a determinação de perdas e ganhos de solo nesse tipo de estudo, evidenciando o depósito de sedimentos na área ciliar coberta de mata, bem como a eficácia dessa formação na retenção dos sedimentos advindos da área de lavoura.
\end{abstract}

Termos indexação: erosão, ${ }^{137} \mathrm{Cs}$, área de preservação permanente, sedimentos.

\footnotetext{
(1) Parte da Tese de Mestrado da primeira autora apresentada à Escola Superior de Agricultura "Luiz de Queiroz" - ESALQ/USP, para obtenção do titulo de mestre em Agronomia, área de concentração: Solos e Nutrição de Plantas. Recebido para publicação em 30 de março de 2010 e aprovado em 27 de junho de 2011.

(2) Doutoranda em Ciências da Escola Superior de Agricultura "Luiz de Queiroz". Perita Federal Agrária do Instituto Nacional de Colonização e Reforma Agrária. Av. Ulisses Guimarães, 640 Salvador (BA). E-mail: dileiasts@usp.br

(3) Professor Titular do Departamento de Solos e Nutrição de Plantas da Escola Superior de Agricultura "Luiz de Queiroz" ESALQ/USP. Caixa Postal 9, CEP 13418-900 Piracicaba (SP). E-mail: gerd@usp.br
} 


\title{
SUMMARY: SEDIMENT RETENTION IN AN AGRICULTURE FIELD BY RIPARIAN FOREST IN GOIATUBA, GOIÁS STATE (BRAZIL)
}

\begin{abstract}
Riparian forests are generally associated to sediment retention and consequently to the mitigation of off-site erosion, but few studies have investigated this effect. The purpose of this study was to analyze the efficiency of riparian forests on the retention of sediment from crop lands using the ${ }^{137}$ Cs technique. Sampling in an area located in Central Brazil, under intensive cotton farming in a conventional system, was performed in July 2005, using cross-sectional analyses. The ${ }^{137}$ Cs technique proved adequate for estimating the soil gains and losses in this kind of study; sediment deposition in the forest-covered riparian area was detected, evidencing the effectiveness of this formation in retaining sediments from crop land.
\end{abstract}

Index terms: erosion, ${ }^{137} \mathrm{Cs}$, area of permanent preservation, sediment.

\section{INTRODUÇÃO}

Matas ciliares são ecótonos entre os ecossistemas terrestre e o aquático e influenciadas por ambos. Têm a função de regular as transferências de energia e nutrientes de um ecossistema para outro (Paula Lima, 1989; Correll, 2001; Kageyama et al., 2002; Cavalcanti \& Lockaby, 2006; Collins, 2010). Também são denominadas como zonas ripárias ou zonas-tampão. Quando localizadas em áreas agrícolas, previnem ou minimizam a movimentação de sedimentos gerados durante o processo erosivo (Addiscott, 1997).

Além de provocar a degradação da área agrícola, a erosão dos solos causa impactos fora do local de sua ocorrência (Lal, 1998), como a contaminação dos cursos d'água pela introdução de partículas de sedimentos e de contaminantes químicos, que aplicados na área agrícola podem ser carreados durante o processo de erosão ligados aos sedimentos (Bertoni \& Lombardi Neto, 1990; Liess et al., 1999; Sparovek et al., 2001a; Harris \& Forster, 2001; Ritter \& Shirmohammadi, 2001; Filizola et al., 2003). Na presença de matas ciliares, parte dos sedimentos carreados deposita-se sobre o solo original e, assim, formam camadas passiveis de serem identificadas por meio de observações morfológicas ou análises físicas (Filippe, 2006; Santos, 2007; Momoli et al., 2007; Pires et al., 2009; Oliveira, 2010), minimizando, no entanto, os impactos da erosão sobre os recursos hídricos.

Considerada uma das práticas vegetativas de mitigação da degradação dos recursos hídricos, a manutenção das matas ciliares é recomendada ou exigida por lei. No caso específico do Brasil, o Código Florestal Brasileiro (Lei 4.771, de 15/09/1965) estabelece faixas de vegetação que devem ser protegidas ao redor dos corpos d'água e nascentes, a título de preservação permanente (APP). A definição das larguras dessas faixas foi estabelecida com pouco suporte científico e sem levar em consideração características específicas da microbacia, como fisionomia da vegetação, estado de degradação da área, tipo do solo, declividade e comprimento da vertente (Filippe, 2006), características que influenciam diretamente na eficiência da mata ciliar em reter sedimentos advindos da área de lavoura.

Estudos sobre a retenção de sedimentos em zonas ripárias em paisagens predominantemente agrícolas são de extrema importância, principalmente, na investigação da efetividade das larguras das faixas ciliares na proteção dos recursos hídricos (Phillips, 1989; Lowrance et al., 1997; Simões, 2001; Sparovek et al., 2001b; Collins et al., 2010), gerando subsídios para o estabelecimento de larguras ótimas de matas ciliares no exercício do papel-filtro na retenção de nutrientes e sedimentos advindos de áreas agrícolas.

Entre os métodos utilizados para o estudo de retenção de sedimentos em matas ciliares, o do ${ }^{137} \mathrm{Cs}$ é apresentado como alternativa para melhor entendimento dos processos de produção e deposição de sedimentos em sistemas agrícolas integrados a zonas ripárias (Pires et al., 2009).

O radionuclídio ${ }^{137} \mathrm{Cs}$, produto da fissão nuclear, foi depositado sobre a superfície terrestre pela precipitação radioativa ("fallout") dos produtos gerados após a detonação dos testes de bombas nucleares. A rápida e forte adsorção do ${ }^{137} \mathrm{Cs}$ nos minerais de argila e na matéria orgânica do solo confere-lhes baixa movimentação vertical, concentrando-se principalmente nas camadas superficiais do solo. Essa particularidade permite relacionar a atividade do ${ }^{137} \mathrm{Cs}$ com a redistribuição dos sedimentos e perdas de solo nos processos erosivos (Walling \& Quine, 1991; Bacchi et al., 2000; Andrello, 2003; Correchel, 2003; Schuller et al., 2004; Mabit et al., 2008; Porto et al., 2009; Estrany et al., 2010).

A técnica estima as taxas de erosão baseadas nas diferenças entre valores dos inventários de ${ }^{137} \mathrm{Cs}$ medidos [atividade total em Bequerél (Bq) por unidade de área] no perfil do solo objeto de estudo e aqueles obtidos em local de referência, sem a ocorrência de processos erosivos. 
Nesse sentido, este trabalho avaliou a redistribuição de solo e a aplicabilidade da técnica do ${ }^{137} \mathrm{Cs}$ para determinar a eficiência da mata ciliar na retenção dos sedimentos gerados na área agrícola cultivada com algodão em uma vertente de intenso uso agrícola no Cerrado brasileiro.

\section{MATERIAL E MÉTODOS}

Aárea de estudo localiza-se na Região Centro-Oeste do país, no município de Goiatuba, GO (latitude $18^{\circ}$ 00' 39" Sul, longitude 49 21' 51" Oeste). Essa localidade possui a fisionomia da vegetação nativa classificada como savana arborizada sob o domínio do bioma Cerrado. O clima é classificado como do tipo AW (Classificação de Köppen), caracterizado como tropical úmido, com duas estações bem definidas, úmida no verão e seca no inverno. As chuvas são concentradas nos meses de janeiro a março, com precipitação pluvial média anual entre 1.200 e 1.800 mm, com as temperaturas máximas e mínimas variando de 40 a $1{ }^{\circ} \mathrm{C}$. A litologia é predominantemente composta por Basalto da formação Serra Geral (JKsg), com o relevo regional variando de suave- ondulado a ondulado, com ocorrência de formação de morros e colinas. $\mathrm{O}$ solo do local de estudo foi classificado como Latossolo Vermelho distrófico (Embrapa, 1999).

A mudança do uso do solo ocorreu na década de 1940, quando a cobertura original de Cerrado foi substituída pelo cultivo de pastagens e, posteriormente, por culturas agrícolas. No ano de 1997, a área passou a ser cultivada com algodão em sistema de plantio convencional, podendo ser observada a ocorrência de terraços de infiltração como medida de conservação do solo, com espaçamento entre os canais de aproximadamente $80 \mathrm{~m}$. A jusante havia uma faixa de mata ciliar remanescente com largura média de $44 \mathrm{~m}$ às margens do córrego do Lajedo. A mata ciliar apresentava bom estado de conservação, sendo comum a ocorrência de árvores de raízes tubulares, que funcionam como barreira ao fluxo de enxurrada, provocando a retenção dos sedimentos.

Para a avaliação da redistribuição do solo na vertente pela técnica do ${ }^{137} \mathrm{Cs}$, foi feita uma amostragem em junho de 2005, em transeção traçada em linha reta partindo do ponto mais baixo da vertente, à beira do curso d'água, passando pela mata ciliar e atingindo parte da área agrícola, de modo a representar os solos e as movimentações de sedimentos. A área de influência direta no transector amostrado (fluxo de enxurrada) determinado por meio do modelo digital do terreno - SRTM (Miranda, 2005) e processado no TNT Mips ${ }^{\circledR}$ - é de 123,35 ha, com a vertente medindo $1.008 \mathrm{~m}$ do curso de água até o topo do morro; a declividade média era de $5 \%$ na transeção estudada (204 m) e 3,6 \% na área de mata ciliar (44 m).
Foram amostrados 10 pontos ao longo da transeção, sendo cinco na área agrícola e cinco na área de mata ciliar. As amostras foram coletadas com o auxílio de um trado, sendo compostas por três subamostras distanciadas $5 \mathrm{~m}$, em linha perpendicular à transeção, nas profundidades de 0 a 20 , de 20 a 40 e de 40 a $60 \mathrm{~cm}$. Especificamente na área de mata ciliar, foram abertas três trincheiras com dimensões de $1 \times 1 \times 1 \mathrm{~m}$, a primeira (AT40) localizada a $40 \mathrm{~m}$ do curso de água e a $4 \mathrm{~m}$ do fim da área de lavoura; a segunda (AT30) localizada a $30 \mathrm{~m}$ do curso de água e a $14 \mathrm{~m}$ do fim da área de lavoura; e a terceira (AT20) situada a $20 \mathrm{~m}$ do curso de água e a $24 \mathrm{~m}$ do fim da área de lavoura. Para a detecção da atividade do ${ }^{137} \mathrm{Cs}$, as trincheiras foram amostradas de $5 \mathrm{em} 5 \mathrm{~cm}$ de profundidade até onde foi evidenciado o depósito de sedimentos, em blocos de $20 \times 20 \mathrm{~cm}$ de lados, obtendo-se aproximadamente $2 \mathrm{~kg}$ de solo.

Para o cálculo de ganho e a perda de solo, fez-se a amostragem de uma área de referência da atividade do ${ }^{137} \mathrm{Cs}$, que em tese não tenha sofrido perda e ganho de solo. Assim foi amostrada uma área localizada na mesma microrregião de estudo com aproximadamente 30 ha, com declividade média de 1,0\% e sob cobertura de pastagem. Essa pastagem, implantada antes de 1962, apresentava boa cobertura do solo e, segundo o proprietário, não foi submetida à reforma desde a sua implantação, minimizando os processos de perda e ganho de solo. Nesse local foram abertas três trincheiras com dimensões de $20 \times 20 \mathrm{~cm}$, sendo o solo coletado em camadas de $5 \mathrm{~cm}$, nas profundidades de $0-5,5-10,10-15,15-20,20-25,25-30$ e 30-35, com a obtenção de um volume de aproximadamente $2.000 \mathrm{~cm}^{3}$ de solo por amostra.

Para as análises da atividade do ${ }^{137} \mathrm{Cs}$, béqueres Marinelli de $1 \mathrm{~L}$ foram preenchidos com TFSA e levados a um detector de Germânio Hiperpuro de alta resolução, modelo GEM-20180P, PopTop (EG\&ORTEC), acoplado a um analisador multicanal.

Os dados de atividade do ${ }^{137} \mathrm{Cs}$ foram convertidos em taxas de perda e ganho de solo por erosão e sedimentação pelo Método Proporcional (Walling \& Quine, 1991; Walling \& He, 1997). Para cada perfil das transeções de estudo foi calculada a diferença do inventário de ${ }^{137} \mathrm{Cs}$ em relação ao inventário médio de ${ }^{137} \mathrm{Cs}$ do local de referência (Equação 1).

$$
\Delta A_{C s}=\left(\frac{A_{C s p}-A_{C s r e f}}{A_{C s r e f}}\right) \cdot 100
$$

em que $\Delta A_{C s}$ é a porcentagem de perda ou ganho de ${ }^{137} \mathrm{Cs}$ e $A_{C s p}$ é o valor do inventário de ${ }^{137} \mathrm{Cs}$ no ponto da transeção, sendo $B q m^{-2}$ e $A_{C s R e f}$ os valores médios dos inventários do local de referência em $B q \mathrm{~m}^{-2}$. Posteriormente foi feita a conversão dos valores dos inventários de ${ }^{137} \mathrm{Cs}$ em taxas de erosão, por meio da equação 2. 


$$
E=\left(\frac{\Delta A_{C s} \times d_{s} \times z}{T F}\right) \cdot 10
$$

em que $E$ é a taxa média anual de erosão, em $\mathrm{Mg}_{\text {ha-1 }}$ ano $^{-1} ; \Delta A_{C s}$ é a porcentagem de perda ou ganho de ${ }^{137} \mathrm{Cs} ; d_{s}$ é a densidade do solo expressa em $\mathrm{kg} \mathrm{m}^{-3} ; z$ é a profundidade da camada arável em $\mathrm{m}$ (tomada como 0,2 m); Té o tempo decorrido desde o início do "fallout" do ${ }^{137} \mathrm{Cs}$, expresso em anos; e $F$ é o fator de correção do tamanho de partículas.

As taxas de erosão calculadas com base no método do ${ }^{137} \mathrm{Cs}$ permitem uma análise retrospectiva dos últimos 41 anos de uso do solo, uma vez que o pico do "fallout" do ${ }^{137}$ Cs no hemisfério sul ocorreu em 1964 (amostragem em 2005). Maior detalhamento do procedimento metodológico de análise de ${ }^{137} \mathrm{Cs}$ está descrito em Bacchi et al. (2000), e Correchel (2003).

Foram feitas observações morfológicas da distribuição dos horizontes nos perfis em cinco trincheiras abertas na área de mata ciliar, três delas utilizadas para a amostragem e detecção da atividade de ${ }^{137} \mathrm{Cs}$ e mais duas complementares (AT10), localizadas a $10 \mathrm{~m}$ do curso de água e a $34 \mathrm{~m}$ do fim da área de lavoura e (AT04) localizada a 4 m do curso de água e a $40 \mathrm{~m}$ do fim da área de lavoura. Amostras de solo foram coletadas em cada camada (horizonte) diferençável morfologicamente e submetidas a análises químicas para fins de fertilidade (Raij et al., 2001) e à análise granulométrica, pelo método do densímetro de Bouyoucos (Kiehl, 1979), utilizando-se solução de $\mathrm{NaOH} 1 \mathrm{~mol} \mathrm{~L}^{-1}$ com dispersão lenta. A figura 1 representa o esquema de amostragem feito em campo para estudo do ${ }^{137} \mathrm{Cs}$, caracterização química e observação morfológica.

Depósitos de sedimentos foram observados na área de mata ciliar. A deposição estendeu- se desde o início da mata até aproximadamente $20 \mathrm{~m}$ mata adentro. $\mathrm{Na}$ primeira trincheira observada (AT40) a $4 \mathrm{~m}$ da área de lavoura, foi possível visualizar duas camadas de sedimentos com espessura de 8 e $14 \mathrm{~cm}$, distintas entre si pela maior compactação da segunda camada de sedimentos; na segunda trincheira observada
(AT30) a 14 m da área de lavoura, uma única camada de sedimentos foi identificada com espessura de $11 \mathrm{~cm}$. $\mathrm{Na}$ terceira trincheira (AT20) localizada a $24 \mathrm{~m}$ da área de lavoura, não foi evidenciada a existência de camada superficial de sedimentos, sendo identificado o horizonte A em superfície.

O quadro 1 apresenta os resultados das análises de fertilidade e granulométrica de amostras coletadas nas trincheiras abertas na área de mata ciliar e mais três pontos na área de lavoura. Cada amostra coletada nas trincheiras representa uma camada (horizonte) diferençável morfologicamente.

\section{RESULTADOS E DISCUSSÕES}

\section{Redistribuição de solo na transeção estudada}

O perfil topográfico e os valores de perda e ganho de solo são apresentados na figura 2 . A média da atividade do ${ }^{137} \mathrm{CS}$ na área de referência é de $161,74 \mathrm{~Bq} \mathrm{~m}^{-2}$ e foi utilizada para o cálculo dos valores de perda e ganho de solo.

Houve deposição de sedimentos em praticamente todos os pontos amostrados, mas apenas em dois pontos (ATr204 e ATr64) na área de lavoura houve perda de solo por erosão. Essa área apresentou valores variando de $37,17 \mathrm{Mg} \mathrm{ha}^{-1}$ ano $^{-1}$ de perda de solo por erosão no ponto ATr64 a 189,68 $\mathrm{Mg} \mathrm{ha}^{-1}$ ano $^{-1}$ de deposição de sedimentos no ponto ATr104.

Na área de mata ciliar, o ponto Atr20, localizado a $24 \mathrm{~m}$ do final da área de lavoura, apresentou o maior valor de deposição de sedimentos, de 484,02 $\mathrm{Mg} \mathrm{ha}^{-1}$ ano-1, enquanto o ponto $\mathrm{ATr} 4$, o menor valor, $154,36 \mathrm{Mg} \mathrm{ha}^{-1} \mathrm{ano}^{-1}$.

Elevados valores de depósitos de sedimentos podem ser atribuídos à dimensão da área de contribuição direta no ponto de coleta de 123,35 ha e à localização da transeção alocada na parte inferior da vertente de $1.008 \mathrm{~m}$ do curso d'água até o topo. A parte superior da vertente na época da amostragem encontrava-se sobre a cobertura de pastagem degradada, o que

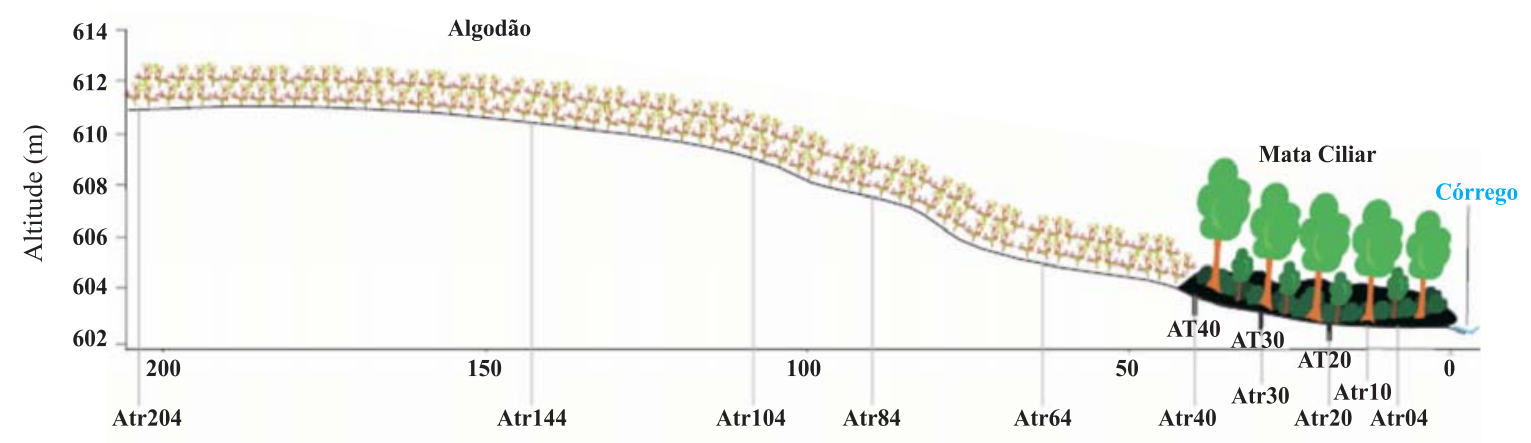

Figura 1. Perfil topográfico da vertente de amostra com a localização das tradagens (Atr) e das trincheiras (AT). Em que AT: trincheira e ATr: tradagens, e o índice numérico indica a distância entre o ponto de amostragem e o curso de água. 
Quadro 1. Caracterizações química e granulométrica das amostras coletadas nas trincheiras alocadas na área de mata ciliar

\begin{tabular}{|c|c|c|c|c|c|c|c|c|c|c|c|c|c|c|}
\hline \multirow{2}{*}{ Camada } & \multirow{2}{*}{ Horiz. } & \multirow{2}{*}{$\mathbf{p H}$} & \multirow{2}{*}{ MO } & \multirow{2}{*}{$\mathbf{P}$} & \multirow{2}{*}{$\mathbf{K}^{+}$} & \multirow{2}{*}{$\mathrm{Ca}^{2+}$} & \multirow{2}{*}{$\mathrm{Mg}^{2+}$} & \multirow{2}{*}{$\mathbf{H}+\mathbf{A l}$} & \multirow{2}{*}{ SB } & \multirow{2}{*}{$\mathbf{T}$} & \multirow{2}{*}{$\mathrm{V}$} & \multicolumn{3}{|c|}{ Granul. - disp., } \\
\hline & & & & & & & & & & & & Arg & Sil & Are \\
\hline $\mathrm{cm}$ & & & $\mathrm{g} \mathrm{dm}{ }^{-3}$ & $\mathrm{mg} \mathrm{dm}{ }^{-3}$ & & & -11 & $\mathrm{ol}_{\mathrm{c}} \mathrm{dm}^{-3}$ & & & & - & & \\
\hline AT204 0-5 & A & 5,21 & 55,18 & 22,2 & 9,7 & 24,33 & 13,33 & 51,04 & 47,35 & 98,39 & 48,12 & 60 & 16 & 24 \\
\hline AT204 5-10 & A & 5,16 & 53,01 & 13,68 & 6,2 & 26,67 & 13,00 & 52,68 & 45,89 & 98,57 & 46,56 & 62 & 14 & 24 \\
\hline AT104 $0-5$ & $\mathrm{~A}$ & 5,00 & 49,29 & 8,28 & 8,0 & 21,00 & 8,33 & 56,7 & 37,32 & 94,02 & 39,69 & 54 & 16 & 30 \\
\hline AT104 5-10 & A & 4,93 & 51,46 & 13,44 & 4,9 & 21,00 & 9,00 & 62,12 & 34,90 & 97,02 & 35,97 & 54 & 18 & 28 \\
\hline AT64 0-5 & A & 5,37 & 48,36 & 10,08 & 7,5 & 23,33 & 10,67 & 42,66 & 41,49 & 84,15 & 49,30 & 56 & 14 & 30 \\
\hline AT64 5-10 & A & 5,24 & 42,47 & 3,6 & 4,5 & 18,50 & 8,50 & 44,19 & 31,49 & 75,68 & 41,61 & 57 & 13 & 30 \\
\hline AT40 $0-8$ & Sed & 5,62 & 63,86 & 24,72 & 10,8 & 60,67 & 18,67 & 44,54 & 90,14 & 134,68 & 66,93 & 60 & 22 & 18 \\
\hline AT40 8-22 & Sed & 5,63 & 48,36 & 16,56 & 5,9 & 42,33 & 12,67 & 40,48 & 60,87 & 101,35 & 60,06 & 58 & 10 & 32 \\
\hline AT40 $22-40$ & A & 5,39 & 69,13 & 22,56 & 3,5 & 61,67 & 20,33 & 50,17 & 85,55 & 135,72 & 63,03 & 58 & 18 & 24 \\
\hline AT40 $40-100$ & $\mathrm{Bw}$ & 4,73 & 40,15 & 5,76 & 2,7 & 9,67 & 8,00 & 66,19 & 20,39 & 86,58 & 23,55 & 68 & 20 & 12 \\
\hline AT30 0-11 & Sed & 5,55 & 58,13 & 23,88 & 5,4 & 47,67 & 13,67 & 43,72 & 66,74 & 110,46 & 60,42 & 52 & 12 & 36 \\
\hline AT30 $11-26$ & $\mathrm{~A}$ & 5,37 & 73,78 & 55,08 & 4,3 & 77,67 & 25,00 & 52,13 & 106,94 & 159,07 & 67,23 & 56 & 20 & 24 \\
\hline AT30 $26-44$ & $\mathrm{~A} / \mathrm{B}$ & 4,40 & 37,67 & 12,72 & 3,7 & 14,67 & 9,33 & 96,37 & 27,74 & 124,11 & 22,35 & 60 & 20 & 20 \\
\hline AT30 $44-100$ & $\mathrm{Bw}$ & 4,18 & 39,99 & 18,60 & 2,9 & 21,67 & 12,67 & 132,66 & 37,20 & 169,86 & 21,90 & 62 & 20 & 18 \\
\hline AT20 0-15 & $\mathrm{A}$ & 6,01 & 83,24 & 45,12 & 5,9 & 113,33 & 30,33 & 33,25 & 149,61 & 182,86 & 81,82 & 68 & 18 & 14 \\
\hline AT20 15-34 & $\mathrm{A} / \mathrm{B}$ & 4,02 & 46,04 & 17,64 & 2,6 & 13,67 & 6,67 & 164,52 & 22,9 & 187,42 & 12,22 & 62 & 26 & 12 \\
\hline AT20 $34-100$ & $\mathrm{Bw}$ & 3,84 & 39,68 & 19,80 & 2,7 & 7,00 & 3,33 & 166,17 & 12,59 & 178,76 & 7,04 & 62 & 26 & 12 \\
\hline AT10 0-5 & A & 4,23 & 49,6 & 18,12 & 2,4 & 14,00 & 6,67 & 130,38 & 23,04 & 153,42 & 15,02 & 64 & 22 & 14 \\
\hline AT10 5-15 & $\mathrm{A} / \mathrm{B}+$ & 4,01 & 36,74 & 10,56 & 1,7 & 5,67 & 2,67 & 122,81 & 10,02 & 132,83 & 7,54 & 58 & 14 & 28 \\
\hline AT04 0-8 & A & 4,97 & 72,70 & 20,16 & 4,5 & 55,00 & 21,33 & 66,88 & 80,79 & 147,67 & 54,71 & 58 & 20 & 22 \\
\hline AT04 8-40+ & $\mathrm{Bw}$ & 4,31 & 44,02 & 17,04 & 2,2 & 20,00 & 9,00 & 113,82 & 31,17 & 144,99 & 21,50 & 44 & 16 & 40 \\
\hline
\end{tabular}

Em que AT: trincheira; o primeiro índice-número indica a distância do ponto de coleta até o curso d'água, enquanto o segundo e o terceiro índice-número separado por hífen indicam a profundidade amostrada.

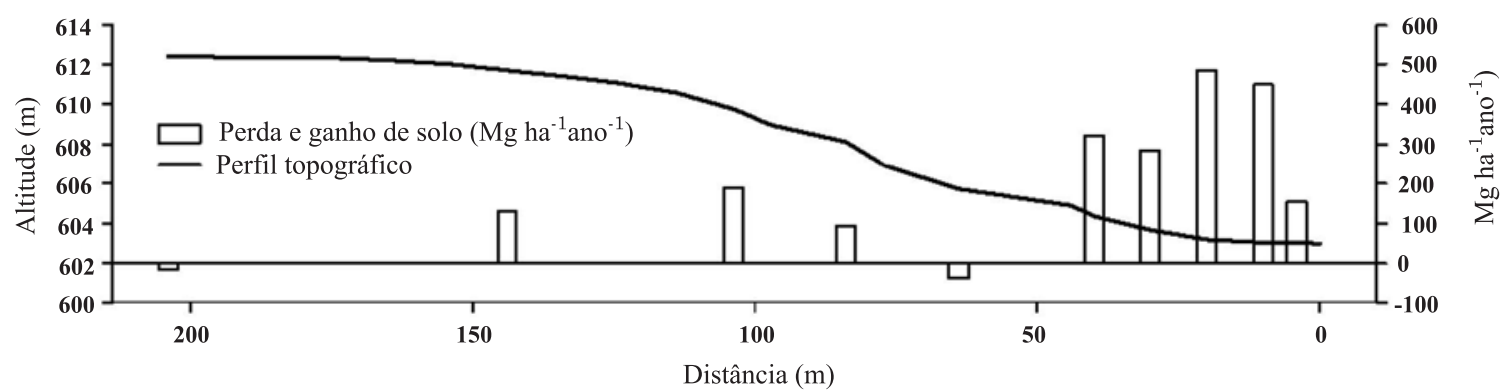

Figura 2. Perfil topográfico com uso do solo, taxa de erosão ( $\mathrm{Mg} \mathrm{ha}^{-1}$ ano $\left.^{-1}\right)$ e análise detalhada da atividade de ${ }^{137} \mathrm{Cs}$ nas trincheiras abertas na área de mata ciliar na transeção 1 .

provavelmente tenha gerado grandes quantidades de sedimentos que foram depositados a jusante nos locais de menor declive, nos terraços de infiltração da área agrícola que atuavam como obstáculo ao fluxo de enxurrada, provocando a deposição dos sedimentos na área de mata ciliar.

Poucos estudos apresentam valores de depósitos de sedimentos em áreas de mata ciliar, e um estudo semelhante utilizando a técnica do ${ }^{137} \mathrm{Cs}$ (Pires et al., 2009) para predizer taxas de redistribuição do solo sugeriu valores na ordem de $160 \mathrm{Mg} \mathrm{ha}^{-1}$ ano $^{-1}$ de deposição de sedimentos na área de mata ciliar, salientando a dificuldade de exatidão desses dados que apresentam valores menores que os esperados tendo em vista a perda de solo da área agrícola. Essas discrepâncias foram atribuídas à possível redistribuição seletiva dos sedimentos finos dentro da mata ciliar e ao decaimento exponencial da atividade de ${ }^{137}$ Cs. Assim, são necessários maiores estudos sobre a aplicabilidade da técnica de ${ }^{137} \mathrm{Cs}$ em solos de florestas e em áreas de deposição de sedimentos.

Os dados de deposição de solo pelo uso da técnica do ${ }^{137} \mathrm{Cs}$ mostram-se discrepantes quando confrontados com os dados obtidos pela descrição morfológica dos perfis. Pela técnica do ${ }^{137} \mathrm{Cs}$, os pontos ATr20 e ATr 10 foram os que apresentaram os maiores valores de deposição de sedimentos, respectivamente 484,02 e $449,79 \mathrm{Mg} \mathrm{ha}^{-1} \mathrm{ano}^{-1}$, com o ponto ATr4 (o mais próximo do curso d'água) apresentando deposição de $154,36 \mathrm{Mg} \mathrm{ha}^{-1}$ ano $^{-1}$. Não se observou em campo a ocorrência de depósitos de sedimentos em nenhum desses pontos. Esses dados refletem a dinâmica da 
deposição dos sedimentos na área de mata ciliar durante o processo erosivo. Era esperado que, de todo o sedimento disperso na água de enxurrada, as frações mais grosseiras fossem as primeiras depositadas (Syversen \& Borch, 2005); no entanto a argila dispersa na água da enxurrada durante o processo erosivo seria a última fração a ser depositada, juntamente com a matéria orgânica, que pode ser transportada tão longe quanto a água, devido à sua baixa velocidade de decantação (Ritter \& Shirmohammadi, 2001). Considerando que ${ }^{137} \mathrm{Cs}$ é um radionúcleo de forte adsorção nos minerais de argila, espera-se que nesses locais seja detectada a maior atividade de ${ }^{137} \mathrm{Cs}$ e, consequentemente, os valores de deposição de sedimentos obtidos por essa técnica sejam mais elevados. Assim, mesmo não sendo observados depósitos de sedimentos nas três últimas trincheiras analisadas (AT20, AT10 e AT4), a hipótese é de que nesses locais tenham ocorrido as maiores deposições de argila enriquecida por ${ }^{137} \mathrm{Cs}$. Essa argila dispersa pode ter percolado, juntamente com a água de enxurrada em profundidade, e impregnado os primeiros centímetros do solo. A análise granulométrica (Quadro 1) revelou teores de 68, 64 e $58 \%$ de argila nas camadas superficiais das respectivas trincheiras.

Os valores de atividade de ${ }^{137} \mathrm{Cs}$ nas trincheiras abertas na área de mata ciliar são apresentados na figura 3 .
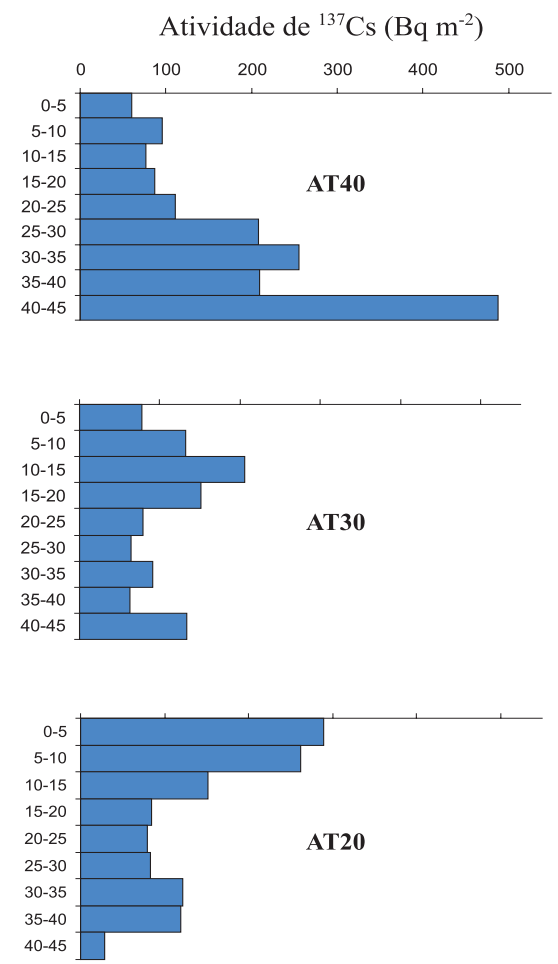

Figura 3. Análise detalhada da atividade de ${ }^{137} \mathrm{Cs}$ nas trincheiras abertas na área de mata ciliar, na transeção estudada.
As análises detalhadas da atividade de ${ }^{137} \mathrm{Cs}$ nas três primeiras trincheiras abertas dentro da mata ciliar revelam diferentes padrões de distribuição da atividade de ${ }^{137} \mathrm{Cs}$. Na AT40 ocorre aumento na atividade de ${ }^{137} \mathrm{Cs}$ com a profundidade, apresentando um pico na última profundidade amostrada de 40 a $45 \mathrm{~cm}$. Na AT30 não houve tendência definida na distribuição da atividade de ${ }^{137} \mathrm{Cs}$ no perfil, sendo observados dois picos principais, um na profundidade de 10 a $15 \mathrm{~cm}$ e outro na de 40 a $45 \mathrm{~cm}$. Na AT20 houve tendência de decréscimo na atividade de ${ }^{137} \mathrm{Cs}$ até os $30 \mathrm{~cm}$, apresentando acréscimo nas camadas de 30 a 35 e 35 a 40 e diminuindo novamente na última camada amostrada.

Comparando esses dados com as descrições morfológicas, na AT40 a partir da superfície, houve aumento na atividade do ${ }^{137} \mathrm{Cs}$, na camada dos 25 aos $40 \mathrm{~cm}$, onde, de acordo com a descrição morfológica, está localizado o horizonte A enterrado, justificando esse aumento. No entanto, após essa camada a profundidade de 45 a $50 \mathrm{~cm}$ apresenta atividade de ${ }^{137} \mathrm{Cs}$ ainda maior, o que não é comum no horizonte B, conforme classificado na observação morfológica, que originalmente na época do "fallout" radioativo (considerando as camadas de sedimentos depositadas pós-"fallout") estaria localizado a $15 \mathrm{~cm}$ da superfície.

Comportamentos similares puderam ser observados nas duas outras trincheiras analisadas. $\mathrm{Na}$ AT30 houve aumento na atividade do ${ }^{137} \mathrm{Cs}$ a partir da profundidade de $10 \mathrm{~cm}$, em que se tem o início do horizonte $\mathrm{A}$ - na descrição morfológica foi classificada como o horizonte localizado entre os 11 e $26 \mathrm{~cm}$. Nas camadas subsequentes ocorreu diminuição progressiva relativamente regular até os $40 \mathrm{~cm}$, com um novo aumento na atividade de ${ }^{137} \mathrm{Cs}$ na camada de 40 a $45 \mathrm{~cm}$. Na AT20, a maior atividade de ${ }^{137} \mathrm{Cs}$ foi observada nas três primeiras camadas analisadas de 0 a 5,5 a 10 e 10 a $15 \mathrm{~cm}$, coincidindo com o horizonte A morfológico. As três camadas subsequentes de 15 a 20,20 a 25 e 25 a $30 \mathrm{~cm}$ apresentaram valores bastante semelhantes entre si e menores que os das camadas superficiais, sendo observado um novo aumento nas camadas de 30 a 35 e 35 a 40 cm, seguido de diminuição significativa na camada de 40 a $45 \mathrm{~cm}$.

Essas diferenças na atividade de ${ }^{137} \mathrm{Cs}$, na maioria das vezes, coincidiram com as diferentes camadas identificadas em campo. Essas evidências sugerem que, apesar de apresentarem características pedológicas nos horizontes $\mathrm{A}$ e $\mathrm{A} / \mathrm{B}$, as camadas identificadas como tal nas descrições morfológicas na verdade correspondem às camadas mais antigas de sedimentos que, com o passar do tempo, sofreram os processos pedológicos, apresentando características de solos.

Em estudo semelhante desenvolvido por Filippe (2006) na região de Iracemápolis, em que foram feitas descrições morfológicas dos solos em área de deposição de sedimentos em floresta ribeirinha, no mesmo perfil analisado foram identificados dois horizontes com 
características de horizonte A. Nesse estudo, a análise de ${ }^{137} \mathrm{Cs}$ efetuada até a profundidade de $60 \mathrm{~cm}$ revelou que houve deposição de sedimentos sobre o horizonte A verdadeiro e que essa camada, com o passar do tempo e submetida aos processos de agregação e de formação de porosidade, passou a apresentar características de horizonte A.

Outra hipótese, no entanto, pode ser levantada, ou seja, os aumentos em subsuperfície na atividade do ${ }^{137} \mathrm{Cs}$ coincidem com o início do horizonte $\mathrm{Bw}$, em que foi detectado aumento no teor de argila em relação aos horizontes superficiais, o que pode ter sido devido à percolação da argila no perfil do solo decorrente dos processos pedológicos e, consequentemente, da lixiviação do ${ }^{137} \mathrm{Cs}$ ligada às partículas de argila. Comportamento semelhante foi observado em estudo desenvolvido por Correchel (2003), em que foi detectada, em uma área de referência, a atividade de ${ }^{137} \mathrm{Cs}$ até a profundidade de $45 \mathrm{~cm}$, ocorrida com pequena fração mais fina do solo.

Para a confirmação das hipóteses levantadas, fazem-se necessárias novas amostragens nessa área, investigando até que profundidade é detectada a atividade de ${ }^{137} \mathrm{Cs}$, o que poderá possibilitar melhor classificação dos horizontes analisados.

\section{CONCLUSÕES}

1. A redistribuição de solo na transeção estudada caracterizou-se por perdas de solo de baixa intensidade e deposições distribuídas de maneira mais dispersa ao longo da área agrícola e também por deposição concentrada e intensa na área de mata ciliar.

2. A mata ciliar mostrou-se eficiente na retenção dos sedimentos gerados na área de lavoura, sendo recomendada a manutenção desse tipo de vegetação como medida mitigadora dos impactos da agricultura sobre os recursos hídricos.

\section{LITERATURA CITADA}

ADDISCOTT, T.M. A critical review of the value of buffer zone environments as a pollution control tool. In: HAYCOCK, N.E.; BURT, T.P.; GOULDING, K.W.T. \& PINAY, G., ed. Buffer zones: Their processes and potential in water protection. Hertfordshire, Quest Environment, 1997. p.236-243.

ANDRELLO, A.C.; APPOLONI, C.R. \& GUIMARÃES, M.F. Uso do Césio - 137 para avaliar taxas de erosão em cultura de soja, café e pastagem. R. Bras. Ci. Solo, 27:223-229, 2003.

BACCHI, O.O.S.; REICHARD, K.; SPAROVEK, G. \& RANIERI, S.B.L. Soil erosion evaluation in small watershed in Brazil thurough $137 \mathrm{Cs}$ fallout revistribution analysis and conventional models. Acta Geogr. Hisp.,35:251-259, 2000.
BRASIL. Congresso Nacional. Código Florestal, Lei No 4.771 de 15.09.1965.

BERTONI, J.\& LOMBARDI NETO, F. Conservação do solo. 1.ed. São Paulo: Ícone, 1990. 355p.

CAVALCANTI, G.G. \& LOCKABY, B.G. Effects of sediment deposition on aboveground net primary productivity, vegetation composition, and structure in riparian forests. Wetlands, 26:400-409, 2006.

COLLINS, A.L.; WALLING, D.E.; McMALLIN, G.K.; ZHANG, Y.; GRAY, J.; McGONIGLE, D. \& CHERRINGTON, R. A preliminary investigation of the efficacy of riparian fencing schemes for reducing contributions from eroding channel banks to the siltation of salmonid spawning gravels across the south west UK. J. Environ. Manag., 91:1341-1349, 2010

CORRELL, D.L. Buffer zones and water quality protection: General principles. In: HAYCOCK, N.E.; BURT, T.P.; GOULDING, K.W.T. \& PINAY, G., ed. Buffer zones: Their processes and potential in water protection. Edgewater, Smithsonian Environmental Research Center, 2001. p.7-20.

CORRECHEL, V. Avaliação dos índices de erodibilidade do solo através da técnica da análise da redistribuição do "fallout" do 137Cs. Piracicaba, Centro de Energia Nuclear na Agricultura, Universidade de São Paulo, 2003. 79p. (Tese de Doutorado)

EMPRESA BRASILEIRA DE PESQUISA AGROPECUÁRIA EMBRAPA. Centro Nacional de Pesquisa do solo. Sistema brasileiro de classificação de solos. Rio de Janeiro, 1999. $412 \mathrm{p}$.

ESTRANY, J.; GARCIA, C. \& WALLING, D.E. An investigation of soil erosion and redistribution in a Mediterranean lowland agricultural catchment using cesium-137. Intern. J. Sed. Res., 25:1-16, 2010.

FILIPPE, J. Avaliação da largura ideal de florestas ribeirinhas considerando modelagem matemática, estimativa de erosão por $137 \mathrm{Cs}$ e aspectos ecológicos. São Paulo, Universidade de São Paulo, 2006.144p. (Tese de Mestrado)

FILIZOLA, H.F.; FERRACINI, V L. \& SANS, L.M.A. Monitoramento e avaliação do risco de contaminação por pesticidas em água superficial e subterrânea na região de Guaíra. Pés. Agrop. Bras. 37:659-667, 2003.

HARRIS, G.L. \& FORSTER, A. Pesticide contamination of surface waters - the potential role of buffer zones. In: HAYCOCK, N.; BURT, T.; GOULDING, K. \& PINAY, G., ed. Buffer Zones: Their processes and potential in water protection. St. Albans, Herts. UK. Ass. Lim., 2001. p.62-69. Disponível em: http://www.biodiversitysouthwest.org.uk/ docs/BufferZones\%28locked\%29.pdf\#page=70. Acesso em 15 de março de 2011.

KAGEYAMA, P.Y.; GANDARA, F.B.; OLIVEIRA, R.E. \& MORAES, L.F.D. Restauração da mata ciliar - Manual para recuperação de áreas ciliares e microbacias. Brasília, Secretaria de Meio Ambiente e Desenvolvimento Sustentável, 2002. 245p.

KIEHL, E.J. Manual de edafológia - Relação solo-planta. São Paulo, Ceres, 1979. 264p. 
LAL, R. Agronomic consequences of soil erosion. In: PENING DE VRIES, F.W.T.; AGUS, F. \& KERR, J.M., ed. Soil erosion at multiple scales: Principles and methods for assessing causes and impacts. London, $\mathrm{CAB}$ International, 1998. p.149-160.

LIESS, M.; SCHULZ, R.; LIESS, M.H.D.; ROTHER, B. \& KREUZIG, R. Determination of insecticide contamination in agricultural headwater streams. Water Res., 33:239247, 1999.

LOWRANCE, R.; ALTIER, L.S.; NEWBOLD, J.D.; SCHANABEL, R.R.; GROFFMAN, P.M.; DENVER, J.M.; CORREL, D.L.; GILLIAN, J.W.; ROBINSON, J.L.; BRONSFIELD, R.B.; STAVER, K.W.; LUCAS, W. \& TODD, A.H. Water quality functions of riparian buffers in Chesapeak Bay watersheds. Environ. Manag., 21:687$712,1997$.

MABIT, L.; BENMANSOUR, M. \& WALLING, D. E. Comparative advantages and limitations of the fallout radionuclides $137 \mathrm{Cs}, 210 \mathrm{PBex}$ and $7 \mathrm{Be}$ for assessing soil erosion and sedimentation. J. Environ. Radioactiv., 99:1799-1807, 2008.

MIRANDA, E.E. coord. Brasil em relevo. Campinas, Embrapa Monitoramento por Satélite, 2005. Disponivel em: http:// www.relevobr.cnpm.embrapa.br/download/go/go.htm. Acesso em 20 de mar. de 2011.

MOMOLI, R.S.; COOPER, M. \& CASTILHO, S.C.P. Sediment morphology and distribution in a restored riparian forest. Sci. Agric., 64:486-494, 2007.

OLIVEIRA, C.A.; KLIEMANN, H.J.; CORRECHEL, V. \& SANTOS, F.C.V. Avaliação da retenção de sedimentos pela vegetação ripária pela caracterização morfológica e físico-química do solo. R. Bras. Eng. Agric. Amb., 14:12811287,2010

PAULA LIMA, W. Função hidrológica da mata ciliar. In. BARBOSA, L.M., coord. In: SIMPÓSIO SOBRE MATA CILIAR, Campinas, 1998. Anais... Campinas, Fundação Cargil, 1998. p.25-42.

PHILLIPS, J.D. An evaluation of the factors determining the effectiveness of water quality buffer zones. J. Hidrol., 107:133-145, 1989.

PIRES, L.F.; BACCHI, O.S.; CORRECHEL, V.; REICHARDT, K. \& FILIPPE, J. Riparian florest potential to retain sediment and carbon evaluated by the ${ }^{137} \mathrm{Cs}$ fallout and carbon isotopic ratio techniques. Agr. Sci., 81:271-279, 2009 .

PORTO, P.; WALLING, D.E.; CALLEGARI, G. \& CAPRA, A. Using caesium-137 and unsupported lead-210 measurements to explore the relationship between sediment mobilisation, sediment delivery and sediment yield for a Calabrian catchment. Marine Fresh. Res., 60:680-689, 2009.
RAIJ, B.van; ANDRADE, J.C.; CANTARELLA, H. \& QUAGGIO, J.A. Análise química para avaliação da fertilidade de solos tropicais. Campinas, Instituto Agronômico de Campinas, 2001. 170p.

RITTER, W.F. \& SHIRMOHAMMADI, A. Agricultural nonpoint source pollution. Boca Raton, CRC Press, 2001. 342p.

SANTOS, D.S. Redistribuição e qualidade de solos e sedimentos agrícolas em vertentes com mata ciliar: Estudo de caso em Goiatuba (GO), Brasil. Piracicaba, Escola Superior de Agricultura "Luiz de Queiroz", Universidade de São Paulo, 2007. 104p. (Tese de Mestrado)

SCHULlER, P.; WALLING, D.E.; SEPULVEDA, A.; TRUMPER, R.E.; ROUANET, J.L.; PINO, I. \& CASTILLO, A. Use of $137 \mathrm{Cs}$ measurements to estimate changes in soil erosion rates associated with changes in soil management practices on cultivated land. Appl. Rad. Isotopes, 60:759-766, 2004.

SIMÕES, L.B. Integração entre um modelo de simulação hidrológica e sistema de informação geográfica na delimitação de zonas tampão ripárias. Botucatu, Universidade Estadual Paulista "Julio de Mesquita Filho", 2001. 125p. (Tese de Doutorado)

SPAROVEK, G.; ANISIMOVA, M.A.; KOLB, M.; BAHADIR, M.; WEHAGE, H. \& SCHNUG, E. Organochloride compounds in a Brazilian watershed with sugarcane and intense sediment redistribution. J. Environ. Qual., 30:2006-2010, 2001a.

SPAROVEK, G.; RANIERI, S.B.L.; GASSNER, A.; DE MARIA, I.C.; SCHNUG, E.; SANTOS, R.F. \& JOUBERT, A. A conceptual framework for the definition of the optimalwidth of riparian forests. Agric. Ecosyst. Environ., 90:169-175, 2001b.

SYVERSEN, N. \& BORCH, H. Retention of soil particle and phosphorus in cold-climate buffer zones. Ecol. Eng., 25:382-394, 2005.

WILLING, D.E. \& HE, Q. Models for converting $137 \mathrm{Cs}$ measurements to estimates of soil redistribution rates on cultivated and uncultivated soil. Exeter, University of Exeter, 1997. 29p.

WALLING, D.E. \& QUINE, T.A. Use of ${ }^{137} \mathrm{Cs}$ measurements to investigate soil erosion on arable fields in the UK: Potential applications and limitations. J. Soil Sci., 42:147165, 1991. 